\title{
The global plastic waste challenge and how we can address it
}

\author{
Jeffrey R. Seay ${ }^{1,2}$ \\ Published online: 11 January 2022 \\ (C) The Author(s), under exclusive licence to Springer-Verlag GmbH Germany, part of Springer Nature 2022
}

Plastic waste and the threat it poses to the environment and public health is perhaps the second biggest global threat after climate change. The lack of effective recycling strategies and effective waste management infrastructure, especially in the developing world, has created a plastic waste crisis. Additionally, policy changes like the 2018 enactment by China of its National Sword policy (Katz 2021), the European Union's ban on shipping waste to developing countries (Euronews 2020), and the amendments to Annexes II, VIII, and IX of the Basel Convention enhancing the control of the transboundary movements of plastic waste (UN Environment Programme 2021a) have left the world scrambling for solutions.

Much of the plastic waste that enters the environment comes from single use items. Nearly half of the plastic produced is only used one then discarded (UN Environment Programme 2021b). The problem of course is that an item used only once is made from a material that persists in the environment for decades or centuries. This plastic is detrimental to animal life who may become entangled in discarded plastic bags, or abandoned fishing nets, or mistake plastic for food. Unfortunately, once an animal has been killed by plastic, the animal decomposes, while the plastic remains, to ensnare the next unsuspecting victim.

In addition to the plastic we can see, a more pervasive threat comes from microplastic. As plastic remains in the environment, it is exposed to UV light, heat, cold, and weathering. Although these forces don't decompose the plastic, they do cause it to break into smaller and smaller pieces. These small pieces are consumed by microorganisms and then begin a journey up the food chain, eventually ending up in human bodies. Recent studies have shown that nearly

Jeffrey R. Seay

jeffrey.seay@uky.edu

1 University of Kentucky College of Engineering, Paducah, KY, USA

2 Engineers for Sustainable Energy Solutions, Paducah, KY, USA all of us have plastic in our bodies (Carrington 2021) and the long-term health impacts are largely unknown.

Since it first entered widespread use, plastic has been exempted from classification as a toxic or hazardous substance. The fact that plastic is so inert does in fact mean that it is not toxic or hazardous in the traditional sense. However, we now know that additives use to modify the properties of commercial plastics can and do leach into the environment. The recent public outcry over the chemical additive BisPhenol A is a case in point. And as described, the impacts of microplastics in the human body are largely unknown. New regulation to classify plastic as a toxic substance is on the horizon and may drastically change how we use and dispose of plastic.

Obviously, to stem the flow of unmanaged plastic waste into the environment, the obviously first step is to use less. Unfortunately, switching to non-plastic alternatives for packaging and other single-use items doesn't come without trade-offs. Metals, glass, cardboard, paper, fabric, and other alternative packaging options are not free of environmental impacts. In addition, these items may be heavier, more prone to breaking, more expensive, or do an inferior job of protecting the product.

Perhaps, more recycling is the answer. Currently only about $9 \%$ of post-consumer plastic is recycled. Certainly, more recycling would help. Again, this is not as simple as it sounds. Recent studies have found that more than 10,000 additives, processing aids, and monomers are used to make plastics, with about 2,400 of those identified as potentially hazardous (Wiesinger et al. 2021). Sorting all these different types of plastic is an impossible task. Furthermore, mechanical recycling shortens polymer chain lengths, meaning that there is a limit to how many times a polymer can be recycled.

Fortunately, despite all the somber news, the world is not without hope in solving the plastic waste crisis. In this special section, contributors offer a wide range of potential solutions. Potential technical solutions like converting post-consumer plastic waste to liquid fuels, selective solvent extraction, and bioplastics and regulatory solutions like bans 
on plastic bags all provide promise for addressing this global crisis.

In conclusion, the proliferation of unmanaged plastic waste into the environmental is a crisis that must be immediately solved. There are certainly challenges and trade-offs that will be encountered. Indeed, plastic are so widely used exactly because they are cheap, lightweight, strong, and nearly infinitely formable. These are properties that are difficult or impossible to achieve with other materials. The stakes are high, given the unknown risks associated with plastics and the additives that are formulated with in our bodies. Despite the difficulty in finding solutions to the plastic waste crisis, new research is showing us that better plastic waste management is possible, as long as this important works begin right away.

\section{References}

Carrington, Damian (2021): Microplastics cause damage to human cells, study shows. The Guardian, https://www.theguardian.com/ environment/2021/dec/08/microplastics-damage-human-cellsstudy-plastic

Euronews (2020): EU bans plastic waste from being shipped to developing countries. https://www.euronews.com/green/2020/12/24/eubans-plastic-waste-from-being-shipped-to-developing-countries

Katz, Cheryl (2021): Piling Up: How China's Ban on Importing Waste Has Stalled Global Recycling. Yale Environment 360, https:// e360.yale.edu/features/piling-up-how-chinas-ban-on-importingwaste-has-stalled-global-recycling

UN Environment Programme (2021a): Basel Convention Plastic Waste Amendments. http://www.basel.int/Implementation/Plasticwaste/ Amendments/Overview/tabid/8426/Default.aspx

UN Environment Programme (2021b): Our planet is drowning in plastic pollution-it's time for change!., https://www.unep.org/inter active/beat-plastic-pollution/

Wiesinger H, Wang Z, Hellweg S (2021) Deep dive into plastic monomers, additives, and processing aids. Environ Sci Technol 55(13):9339-9351

Publisher's Note Springer Nature remains neutral with regard to jurisdictional claims in published maps and institutional affiliations. 